\title{
PROSES KEBIJAKAN PERSUTERAAN ALAM DI SULAWESI SELATAN
}

\author{
Policy Process of Sericulture in South Sulawesi \\ Andi Sadapotto ${ }^{\boxplus}$ \\ Lab. Pemanfaatan dan Pengolahan Hasil Hutan, Fakultas Kehutanan Universitas Hasanuddin, \\ JI. Perintis Kemerdekaan Km. 10 Tamalanrea, Makassar 90245
}

\begin{abstract}
Production of cocoon and raw silk in South Sulawesi have decreased in recent years. One of the problem is misleading policy formulation and implementation. The purpose of this studies is to know the policy of sericulture that have implemented in South Sulawesi. The method of analyses are discourse analysis/narrative, actors/network, and politics/ interest. The result indicated that three factors ie. narrative, actors and interests among stakeholder in sericulture development disturb the policy implementation so it wouldn't achieve the goal. Incorrect problem formulation also disrupt the sericulture development so it didn't increase cocoon and raw silk production in South Sulawesi.
\end{abstract}

Key words: policy, process, sericulture, South Sulawesi

\section{PENDAHULUAN}

Kegiatan budidaya sutera alam sudah dipraktekkan oleh masyarakat di Sulawesi Selatan sejak tahun 1950-an. Kegiatan budidaya sutera alam terdiri dari rangkaian kegiatan budidaya murbei dan pemeliharaan ulat sutera yang pada umumnya dilakukan oleh masyarakat pedesaan sebagai sumber pendapatan tambahan. Kegiatan budidaya murbei dan pemeliharaan ulat sutera Pengembangan ulat sutera telah lama dilaksanakan oleh sebagian masyarakat di pedesaan di Sulawesi Selatan. Walaupun demikian, produktvitas tidak pernah meningkat. Berbagai kebijakan telah diluncurkan oleh pemerintah untuk meningkatkan produksi persuteraan alam di Sulawesi Selatan tapi belum mencapai target yang diharapkan. Berbagai kebijakan yang diluncurkan tidak pernah sesuaitarget karena berbagai alasan. Latar belakang berbagai kebijakan tersebut tidak pernah menunjukkan berbagai kepentingan, aktor dan jaringan yang saling terkait satu sama lain. Tujuan penelitian ini adalah untuk (1) mengetahui kebijakan persuteraan alam yang pernah diterapkan di Sulawesi Selatan,

Diterima: 2 Agustus 2011; Disetujui: 21 November 2011

$\square$ Penulis korespondensi (corresponding author): sadapotto@yahoo.com
(2) menganalisis diskursus, aktor dan jaringan, dan politik dan kepentingan pada kegiatan persuteraan alam. Kegunaan penelitian ini sebagai bahan pertimbangan dalam pengambilan kebijakan dalam bidang persuteraan alam.

\section{BAHAN DAN METODE}

Penelitian ini dilaksanakan pada bulan Januari 2008 sampai September 2008 di Sulawesi Selatan. Alat dan bahan yang digunakan dalam penelitian ini adalahalattulis, perekamsuara, kuesionerterstruktur. Data yang dikumpulkan berupa data primer dan sekunder. Data primer berupa wawancara dengan pelaku persuteraan alam di Sulawesi Selatan. Data sekunder diambil dari laporan, studi terdahulu dan melalui studi dokumentasi. Analisis data dilakukan secara kualitatif dengan menggunakan metode analisis proses kebijakan menurut IDS (2006). Analisis proses kebijakan menggunakan tiga konsep dan pendekatan yang saling berhubungan yaitu:

1. Pengetahuan dan diskursus (apa narasi kebijakannya? bagaimana dikerangkakan melalui ilmu pengetahuan dan penelitian ?)

2. Aktor dan jaringan (siapa yang terlibat dan bagaimana mereka terhubungkan?)

3. Politik dan kepentingan (apa yang mendasari dinamika kekuasaan?) 


\section{HASIL DAN PEMBAHASAN}

Hasil penelitian menunjukkan bahwa kebijakan persuteraan alam di Indonesia pada umumnya dan Sulawesi Selatan pada khususnya terbagi atas 3 periode yaitu Periode Kebijakan Kerjasama Teknis Indonesia-Jepang (1974-1984), Periode Kredit Usahatani Persuteraan Alam (1997-2000) dan Periode Klaster Persuteraan Alam (2006sekarang).

\section{Periode Kebijakan Kerjasama Teknis Indonesia-} Jepang (1974-1984)

\section{Narasi kebijakan}

Persuteraan alam di Sulawesi Selatan dimulai pada sekitar tahun 1950-an. Pada waktu itu tentara dari Pulau Jawa membawa bibit ulat sutera untuk dikembangkan khususnya di pedesaan. Pemeliharaan ulat sutera kemudian berkembang pesat karena selain kondisi agroklimat yang sesuai juga budaya yang menunjang dalam hal pakaian adat yang memakai bahan sutera. Produksi benang sutera mencapai puncaknya pada tahun 1971 dengan produksi sebesar 140 ton benang sutera. Kemudian setelah itu produksi menurun karena berbagai faktor. Salah satu penyebab adalah meledaknya penyakit pebrine yang menyebabkan matinya ulat sutera dalam pemeliharaan. Pemerintah kemudian melarang penggunaan bibit lokal dan menganjurkan penggunaan bibit bivoltine yang diimpor. Pemerintah kemudian mengadakan kerjasama dengan Jepang (JICA) yang selanjutnya memberikan bantuan hibah berupa bantuan teknik yang ditempatkan di lima kabupaten di Sulawesi Selatan yaitu Enrekang, Soppeng, Wajo, Sidrap dan Gowa disertai dengan expert dari Jepang. Selain itu dari staf dari Indonesia diberi kesempatan magang ke Jepang untuk mempelajari teknis pembibitan ulat sutera, budidaya murbei, pemeliharaan ulat sutera dan pemintalan.

\section{Aktor dan Jaringan}

Dalam bidang persuteraan alam, pihak yang terlibat antara lain Departemen Kehutanan, Departemen Perindustrian. Pada kebijakan kerjasama teknik antara Pemerintah Indonesia dan Jepang yang terlibat dalam hal ini adalah
Departemen Kehutanan dan JICA. Aktor yang terlibat antara lain Departemen Kehutanan, JICA, perguruan tinggi. Pihak perguruan tinggi berpendapat bahwa program kerjasama teknik Indonesia-Jepang tidak menyelesaikan masalah karena berbagai hal. Pemagangan staf proyek persuteraan alam selama 8 bulan di Jepang dan selanjutnya dibimbing oleh Jepang, tidak cukup menghasilkan tenaga teknis persuteraan alam yang mampu menghasilkan teknologi persuteraan alam di Indonesia karena ilmu persuteraan alam alam mencakup ilmu yang lebih luas antara lain ilmu serangga genetik, fisiologi, ekologi, ilmu budidaya murbei, breeding murbei. Kemudian kebijakan pelarangan bagi masyarakat untuk memelihara bibit polyvoltine akan mematikan gairah masyarakat, karena mereka selama ini yang memproduksi sendiri bibit ulat, kalau yang ditakutkan penyakit pebrine maka bisa ditempuh upaya-upaya pencegahan di level masyarakat (komunikasi pribadi, 15 Pebruari 2007) $)^{1}$.

\section{Politik dan Kepentingan}

Pihak Jepang sebagai pemberi hibah mempunyai kepentingan membantu Indonesia mengembangkan persuteraan alam karena Jepang sangat membutuhkan sutera sebagai bahan pembuatan kimono dan baju sutera, sementara produksi sutera dalam negerinya terus menurun karena sifat pemeliharaan ulat sutera yang padat karya sedangkan rakyatnya mengalami pergeseran menuju negara maju yang dicirikan dengan upah tenaga kerja yang mahal (komunikasi pribadi, 20 Pebruari 2007) $)^{2}$. Selain Indonesia negara lain yang dibantu antara lain Thailand, Brazil. Pemerintah Indonesia juga berkepentingan dengan bantuan Jepang karena melihat animo masyarakat untuk memelihara ulat sutera terutama di Sulawesi Selatan yang sangat besar.

\section{Ruang Kebijakan}

Untuk memperbaiki kebijakan ini maka peluang tetap ada dalam hal penggunaan bibit polyvoltine, karena pengalaman di India juga mengembangkan jenis polyvoltine (Kiyokawa, 1993; Kumaresan et al., 2007; Rao et al., 2006), walaupun produktivitas dan kualitasnya lebih rendah dibanding jenis bivoltine,

\footnotetext{
Prof. Mappatoba Sila, pakar serangga berguna dari Universitas Hasanuddin.

2 Dr. Huo Yongkang, pakar persuteraan alam dari China.
} 
tetapi mempunyai kelebihan yaitu mempunyai daya tahan yang tinggi terhadap kondisi suhu yang ekstrim dan penyakit.

\section{Periode Kredit Usahatani Persuteraan Alam (1997-2000)}

\section{Narasi Kebijakan}

Untuk mendorong pengembangan usaha persuteraan alam, sejak tahun 1997 Departemen Kehutanan telah menyediakan Kredit Usahatani persuteraan alam kepada petani yang dituangkan dalam SK Menhut No. 50/Kpts-II/97. Pengembangan Kredit Usahatani Persuteraan Alam dilakukan pada daerah pusat-pusat produksi benang sutera pada 20 kabupaten di 5 propinsi yaitu Sumatera Barat, Jawa Barat, DI Yogyakarta, Jawa Tengah dan Sulawesi Selatan. Sampai tahun 2000 jumlah penerima KUPA sebanyak 8.364 KK dengan luas lahan $6.827,5$ ha. Pemberian kredit diberikan dalam bentuk modal kerja dan sarana produksi dengan bunga yang sangat rendah yaitu 6 persen per tahun. Bantuan permodalan disalurkan oleh pemerintah melalui pihak ketiga atau mitra yaitu badan usaha yang prosesnya melalui penunjukan langsung oleh Departemen Kehutanan.

Dalam pelaksanaan kegiatan pemberian KUPA ini terjadi kemacetan dalam pengembalian dana. Menurut petani penerima KUPA, dana yang disalurkan tidak semuanya diterima oleh mereka dan ada yang tertahan oleh pihak mitra sehingga mereka tidak maksimal dalam melakukan proses produksi. Sedangkan menurut mitra, permasalahan terletak pada petani karena adanya petani yang telah menerima KUPA, tetapi tidak melaksanakan pertanaman ataupun bila melaksanakan luasan pertanaman murbei yang ada di lapangan lebih kecil dari luasan terdaftar, adanya petani yang pada awalnya aktif melakukan pertanaman murbei untuk memancing kucuran dana dapat berjalan lancar, setelah menerima kucuran dana sesuai plafon, mereka meninggalkan tanamannya dan tidak melakukan aktifitas persuteraan alam dan kewajiban pengembalian KUPA yang telah jatuh tempo tidak dihiraukan, terlebih bagi hasil yang diharapkan mitra. Ada petani yang menganggap KUPA identik dengan KUT dan berusaha untuk menunggak dan menunggu pemutihan (PT Kokon Sutera Sulawesi, 2002). Perilaku tersebut oleh Williamson (1985) disebut perilaku oportunis. Pihak mitra juga mengeluhkan sistem KUPA ini dimana mereka tidak mendapatkan imbalan dalam proses penyaluran KUPA ini. Menurut staf Balai Persuteraan Alam, kekurangan dari KUPA ini adalah tidak adanya sanksi bagi penunggak.

\section{Aktor dan Jaringan}

Aktor yang terlibat dalam program pemberian bantuan kredit usahatani persuteraan alam antara lain Departemen Kehutanan, badan usaha sebagai mitra penyalur dan petani penerima. Proses penyaluran KUPA banyak keganjilan di lapangan karena prosesnya serba cepat dan kadang tidak memenuhi prosedur karena pada waktu merupakan periode transisi dari orde baru ke orde reformasi sehingga koridor hukum tidak dipatuhi.

\section{Politik dan Kepentingan}

Dalam periode ini pemerintah dalam hal ini Departemen Kehutanan meluncurkan program Kredit Usahatani Persuteraan Alam. Sasaran program ini adalah petani murbei dan pemeliharan ulat sutera. Proses pemilihan mitra kelihatannya tidak terlalu ketat karena dilihat dari pengalaman mitra yang seharusnya mempunyai pengalaman dalam pembinaan petani sutera. Pada masa ini dikenal sebagai masa transisi dari orde baru ke orde reformasi dimana proses pengawasan tidak terlalu ketat dan Dana Reboisasi juga dipakai untuk kepentingan non-kehutanan seperti biaya pembuatan pesawat terbang. Bersamaan dengan program KUPA ini juga terdapat program lain seperti KUKDAS (Kredit Usaha Konservasi Daerah Aliran Sungai) dan KUHR (Kredit Usaha Hutan Rakyat) yang kondisinya sama dengan KUPA (Raswa, 2007).

\section{Ruang Kebijakan}

Masih ada peluang untuk memperbaiki kebijakan pemberian kredit ini dengan memperbaiki mekanisme penyaluran dan pendampingan, kontrak antara mitra dengan petani, dan sangsi yang jelas sehingga kredit yang diberikan bisa dimanfaatkan sebaik-baiknya.

\section{Periode Klaster Persuteraan Alam (2006- sekarang)}

\section{Narasi kebijakan}

Dalam rangkapengembangan persuteraanalam di Indonesia, pemerintah mengeluarkan kebijakan 
peraturan bersama Menteri Kehutanan, Menteri Perindustrian, dan Menteri Negara Koperasi dan Usaha Kecil Menengah No. : P.47/Menhut-II/2006, No.:29/M-Ind/Per/6/2006, No.:07/Per/M.KUKM/ $\mathrm{VI} / 2006$ Tentang pembinaan dan pengembangan persuteraan alam Nasional dengan Pendekatan Klaster. Pengembangan persuteraan alam dengan pendekatan klaster merupakan program yang melibatkan tiga departemen yaitu Departemen Kehutanan, Departemen Perindustrian dan Kementerian Koperasi dan UKM. Pengembangan persuteraan alam selama ini sudah dilakukan oleh ketiga institusi hanya saja masing-masing berjalan dengan program sendiri-sendiri. Pada pola pengembangan ini pemerintah mencoba membuat kebijakan terpadu dalam satu pola yaitu pola klasterisasi.

Depperin (2006e) dalam Tarigan (2008) mendefinisikan klaster sebagai kelompok yang secara geografis berdekatan, yang terdiri dari perusahaan-perusahaan dan institusi-institusi terkait dalam bidang tertentu, yang dihubungkan dengan adanya kebersamaan (commonalities) dan sifat saling melengkapi (complementaries) satu sama lain. Sedangkan, Porter (1998a) dalam Tarigan (2008) menyatakan bahwa klaster adalah suatu kelompok perusahaan yang saling terkait satu dengan lainnya (interconnected) memiliki asosiasi kelembagaan dalam satu bidang tertentu yang saling melengkapi, kompetitif dan kooperatif.

Pengembangan klaster persuteraan alam di Sulawesi Selatan bermanfaat bagi para pelaku usaha, pembina dan stakeholder persuteraan alam dalam rangka mendorong terbentuknya jaringan kerjasama antar pelaku, saling berkait dan berkolaborasi sehingga memiliki connectivity dan sinergi yang kuat, serta meningkatkan daya saing. Tujuannya adalah untuk meningkatkan penguatan struktur industri dan peningkatan daya saing persuteraan alam (Andikarya, 2007).

Pengembangan persuteraan alam nasional penting karena memiliki backward linkage dan forward linkage yang cukup panjang, menyerap banyak tenaga terdidik dan kurang terdidik, menghasilkan nilai tambah tinggi dengan rantai nilai yang panjang dari hulu sampai hilir, meningkatkan pendapatan daerah dan devisa serta melibatkan berbagai instansi terkait, pelaku usaha dan masyarakat luas (Peraturan Bersama Menteri Kehutanan, Menteri Perindustrian dan Menteri Koperasi dan UKM, 2006).

\section{Aktor dan Jaringan}

Aktor yang terlibat dalam program klaster persuteraan alam ini adalah Departemen Perindustrian, Departemen Kehutanan, Departemen Koperasi dan Usaha Kecil Menengah. Kebijakan klaster adalah kebijakan nasional persuteraan alam yang digeneralisasi pada semua wilayah. Kebijakan ini tidak cocok diterapkan di Kabupaten Wajo karena pengusaha masing-masing mempunyai strategi dalam berusaha dan tidak bisa disatukan dan menganggap bahwa tiap perusahaan mempunyai rahasia perusahaan. Selain itu, pembentukan pokja hanya mengandalkan pengurus daerah dan beban operasional seharusnya ditanggung pemerintah. Akibatnya kebijakan ini tidak berjalan baik di Kabupaten Wajo, padahal Kabupaten Wajo adalah sentra pertenunan sutera di Sulawesi Selatan.

\section{Politik dan Kepentingan}

Kebutuhan akan benang sutera dalam negeri yang cukup besar memaksa pengusaha mengimpor benang sutera terutama dari Cina. Pemerintah berkepentingan untuk mengurangi impor benang sutera dan sekaligus melihat peluang industri persuteraan alam yang melibatkan banyak tenaga kerja baik terdidik maupun tidak terdidik. Pemerintah dalam hal ini Departemen Perindustrian sebagai inisiator kebijakan mencoba menerapkan pola klasterisasi seperti yang diterapkan pada komoditas lain.

\section{Ruang Kebijakan}

Kebijakan nasional klaster persuteraan alam perlu mempertimbangkan karakteristik daerah misalnya Kabupaten Wajo karena karakteristik pengusahanya yang berbeda dengan daerah lain dalam hal pemasaran produk dan inovasi produk untuk meningkatkan nilai tambah produk. Pengusaha menginginkan pemasaran keluar negeri karena pemasaran dalam negeri khususnya industri pertenunan di Jawa masing-masing sudah mempunyai pemasok. Kelompok kerja berpendapat bahwa suara mereka juga perlu didengar dalam rangka peningkatan kuantitas dan kualitas produksi dan juga inovasi produk untuk meningkatkan nilai tambah produk.

\section{KESIMPULAN}

Dari ketiga periode kebijakan persuteraan alam tersebut, terlihat bahwa dalam proses pengambilan 
kebijakan sebenarnya merupakan kontestasi dari pihak-pihak yang berkepentingan dalam kebijakan tersebut. Karena prosesnya yang merupakan persaingan antar pihak, maka pelaksanaannya pun kadang mengakomodasi kepentingan para pelaku usaha. Akibatnya adalah hasil yang diharapkan dari kebijakan tersebut tidak sesuai dengan harapan.

Penyebab tidak berhasilnya kebijakan dalam pengendalian institusi karena salah dalam formulasi masalah. Dalam formulasi masalah, yang selalu dianggap adalah faktor fisik teknis dan mengabaikan faktor institusi, walaupun sudah diketahui bahwa pengusahaan sutera alam adalah padatkarya (labour intensive) sehingga faktor manusia yang terlibat di dalamnya sangat penting dalam keberhasilan usaha tersebut. Terdapat lima faktor penyebab sehingga para pengambil keputusan senantiasa memecahkan masalah yang salah, yaitu konsultasi dengan orang-orang yang tidak tepat, selalu berkaca pada masalah di masa lalu, lebih memperhatikan gejala daripada penyebabnya, terlalu banyak berpikir struktural daripada fungsional, serta hanya terfokus pada bidang atau unit kerja tertentu.

\section{DAFTAR PUSTAKA}

Andikarya, O. 2007. Kemandirian Usaha dengan Pola Klaster Industri Sutera Alam di Sulawesi Selatan. Makalah pada Temu Usaha Persuteraan Alam Sulawesi Selatan. Makassar 11 Desember 2007.

[IDS] Institute of Development Studies. 2006. Understanding Policy Process; A Review of IDS Research on The Environment. Brighton : Institute of Development Studies of University of Sussex.

Kartodihardjo, H. 2010. Masalah Menentukan Masalah. Duta Rimba 33 : $26-27$.

Raswa, E. 2007. Ratusan Miliar Kredit Kehutanan Tidak Jelas. Http://www.temponteraktif.com [diakses tanggal 5 Maret 2009].

Tarigan, D. 2008. Strategi Pengembangan Agroindustri Sutera Alam Melalui Pendekatan Klaster. [disertasi]. Bogor : Sekolah Pascasarjana IPB.

Williamson, O. E. 1985. The Economic Institutions of Capitalism. Firm, Markets and Relational Contracting. New York : The Free Press. 